\title{
hsp70-DnaJ chaperone pair prevents nitric oxide- and CHOP-induced apoptosis by inhibiting translocation of Bax to mitochondria
}

\author{
T Gotoh ${ }^{*, I}$, K Terada $^{1}$, S Oyadomari ${ }^{1}$ and M Mori ${ }^{1}$ \\ ${ }^{1}$ Department of Molecular Genetics, Graduate School of Medical Sciences, \\ Kumamoto University, Honjo, Kumamoto, Japan \\ * Corresponding author: T Gotoh, Department of Molecular Genetics, Graduate \\ School of Medical Sciences, Kumamoto University, Honjo 1-1-1, Kumamoto \\ 860-8556, Japan. Tel: + 81-96-373-5140; Fax: + 81-96-373-5145; \\ E-mail: tomomi@gpo.kumamoto-u.ac.jp
}

Received 08.5.03; revised 14.7.03; accepted 05.8.03; published online 30.1.04 Edited by Dr H Ichijo

\begin{abstract}
We reported that the endoplasmic reticulum (ER) stress pathway involving CHOP, a member of the C/EBP transcription factor family, plays a key role in nitric oxide (NO)-mediated apoptosis of macrophages and pancreatic $\beta$ cells. We also showed that the cytosolic chaperone pair of hsp70 and dj1 (hsp40/hdj-1) or dj2 (HSDJ/hdj-2) prevents NO-mediated apoptosis upstream of cytochrome $c$ release from mitochondria. To analyze roles of the chaperone pair in preventing apoptosis, RAW 264.7 macrophages stably expressing hsp70 and dj1 or dj2 were established. The chaperone pair prevented LPS/IFN- $\gamma$-induced and NO-mediated apoptosis downstream of CHOP induction. hsp70 mutant protein lacking the ATPase domain or the C-terminal EEVD sequence were not effective in preventing $\mathrm{CHOP}$-induced apoptosis. A mutant dj2 lacking the C-terminal prenylation CaaX motif, was also not effective. When wild-type RAW 264.7 cells were treated with LPS/IFN- $\gamma$, NOmediated apoptosis was induced, and proapoptotic Bcl-2 family protein Bax was translocated from cytosol to mitochondria. This translocation was prevented in cells stably expressing hsp70/dj2, and in CHOP knockout cells. Overexpression of CHOP in wild-type cells also induced translocation of Bax and this translocation was prevented in cells expressing hsp70/dj2. CHOP-induced apoptosis was prevented by Bax knock-down. Coimmunoprecipitation experiments showed that Bax interacts with both hsp70 and dj1/dj2. ATPase domain of hsp70 was necessary for the binding with Bax. These findings indicate that CHOP-induced apoptosis is mediated by translocation of Bax from the cytosol to the mitochondria, and hsp70/dj1 or dj2 chaperone pair prevents apoptosis by interacting with Bax and preventing translocation to the mitochondria.

Cell Death and Differentiation (2004) 11, 390-402. doi:10.1038/ sj.cdd. 4401369

Published online 30 January 2004
\end{abstract}

Keywords: apoptosis; Bax; CHOP; molecular chaperone; nitric oxide
Abbreviations: ER, endoplasmic reticulum; ERSE, ER stress response element; GAPDH, glyceraldehyde 3-phosphate dehydrogenase; IFN $\gamma$, interferon- $\gamma$; LPS, lipopolysaccharide; NO, nitric oxide

\section{Introduction}

Nitric oxide (NO) is a multifunctional biomolecule involved in a variety of physiological and pathological processes. ${ }^{1}$ Excess NO production is toxic to the host, and is considered to cause diseases such as septic shock, autoimmune diseases, cerebral infarction, and diabetes mellitus. NO-mediated apoptosis is often observed in such cases. ${ }^{2-4} \mathrm{NO}$ has cytotoxic effects, including reactions with proteins and nucleic acids. NO-induced apoptosis was generally considered to be mediated by DNA or mitochondrial damages; however, the cascade of the cell death has not been clarified. We recently found that the endoplasmic reticulum (ER) stress pathway involving CHOP plays a key role in NO-mediated apoptosis in pancreatic $\beta$ cell, ${ }^{5}$ microglia, ${ }^{6}$ and macrophages. ${ }^{7}$ We also showed that p90ATF6, an ER membrane-bound transcription factor involved in ER stress response, is cleaved to its active soluble form p50ATF6, which is transported to the nucleus and activates transcription of the CHOP gene in LPS/IFN $\gamma$ induced apoptosis. ${ }^{7}$ We showed that a dominant-negative form of CHOP prevents p50ATF6- and LPS/IFN $\gamma$-induced apoptosis, and that NO-induced apoptosis is prevented in CHOP knockout cells. ${ }^{5,7}$ These results show that ATF6 and $\mathrm{CHOP}$ are involved in NO- and LPS/TFN $\gamma$-induced apoptosis.

CHOP, also known as GADD153, is a member of the C/ EBP family that heterodimerizes with other members of the $\mathrm{C} /$ EBP transcription factor family. CHOP is involved in the process of apoptosis associated with ER stress. ${ }^{8-12}$ In ER stress, the activated ATF6 induces ER chaperones, CHOP, and another bZIP-type transcription factor XBP1 via direct binding to the ERSE (ER stress-responsive element). ${ }^{13-15}$ The spliced form of XBP1, produced from induced XBP1 mRNA by the action of an activated ER-membrane protein IRE $1 \alpha$, further enhances transcription of the ER chaperone genes via direct binding to the ERSE. On the other hand, Fawcett et al. ${ }^{16}$ reported that the CHOP gene can be activated by ATF4, another bZIP-type transcription factor, via its binding to the C/EBP-ATF site present in the CHOP promoter region that is distinct from the ERSE. In addition, Harding et al. ${ }^{17}$ reported that translation of ATF4 is selectively increased during ER stress and that this translational induction is mediated by PERK, a type 1 transmembrane protein kinase in the ER, which senses ER stress and transmits signals by phosphorylating the $\alpha$ subunit of eukaryotic initiation factor 2.

CHOP induces apoptosis in some cell types. ${ }^{9}$ Embryonic fibroblasts derived from CHOP-knockout mice exhibit 
significantly less apoptosis compared with wild-type cells, when challenged with ER stress-inducing reagents. ${ }^{9} \mathrm{CHOP}$ was found to induce apoptosis in M1 myeloblastic leukemia cells in a p53-independent manner and $\mathrm{Bcl}-2$ delayed this process. ${ }^{18}$ Because $\mathrm{CHOP}$ functions as a transcription factor, there must be a target gene(s), the transcription of which is activated by $\mathrm{CHOP}$, and whose product(s) functions in the apoptosis signal cascade. Wang et al. ${ }^{19}$ found candidate target genes of the CHOP protein when using representational difference analysis. However, these genes are distinct from known factors involved in the ER stress response and apoptosis. McCullough et al. ${ }^{20}$ reported that CHOP expression results in downregulation of Bcl-2 expression, depletion of cellular glutathione, and exaggerated production of reactive oxygen species. However, the precise apoptosis cascade downstream of CHOP is unknown.

Heat-shock proteins (hsps) induced in response to various stresses afford protection. ${ }^{21,22}$ The major hsps can be divided into several groups based on both size and function. ${ }^{23}$ Some constitutively expressed hsps act as molecular chaperones. Members of the hsp70 family are involved in the folding and intracellular transport of newly synthesized proteins. ${ }^{24,25}$ To protect cells from various stresses, hsp70s bind to damaged and misfolded proteins, and either facilitate their refolding or target severely damaged proteins for degradation. ${ }^{21}$ hsp70 also protects cells from apoptosis induced by various stresses and agents, including NO, oxidative stress, tumor necrosis factor, anticancer drugs, ceramide and radiation. ${ }^{21}$ There are several reports concerning the antiapoptotic effects of hsp70. However, the mechanism of antiapoptotic effects of hsp70 is not fully understood. DnaK, the hsp70 homolog of Escherichia coli, is regulated by partner chaperones, DnaJ and GrpE. ${ }^{25,26}$ Several mammalian DnaJ homologs (hsp40 family members) have been identified, ${ }^{27}$ and it seems likely that hsp70 family members are regulated by these homologs. ${ }^{28}$ Major DnaJ homologs in mammalian cytosol are dj1 (DNAJB1: hsp40/ hdj-1) and dj2 (DNAJA1: HSDJ/hdj-2). We reported that dj1hsp70 and dj2-hsp70 chaperone pairs are both effective in preventing NO-mediated apoptosis upstream of both caspase 3 activation and cytochrome $c$ release from the mitochondria. $^{29}$

Here we report that CHOP induces apoptosis in RAW 264.7 macrophages through translocation of a proapoptotic Bcl-2 family protein Bax from the cytosol to the mitochondria. We also found that the hsp70/DnaJ chaperone pair prevents CHOP-mediated apoptosis by interacting with Bax and by preventing its translocation from the cytosol to the mitochondria.

\section{Results}

\section{hsp70/DnaJ chaperone pairs prevent NO-mediated apoptosis downstream of CHOP induction in RAW} 264. 7 cells

When mouse macrophage-like RAW 264.7 cells were treated with $E$. coli lipopolysaccharide (LPS) and interferon- $\gamma($ IFN- $\gamma$ ), inducible NO synthase (iNOS) is highly induced and a large amount of $\mathrm{NO}$ is produced. Under these conditions, apoptosis occurs. ${ }^{30}$ We reported that the hsp70/DnaJ chaperone pairs prevent this apoptosis upstream of the cytochrome $c$ release from the mitochondria. ${ }^{29}$ To clarify the precise antiapoptotic mechanism of hsp70/DnaJ chaperone pairs, we established stably transformed RAW 264.7 cell lines expressing hsp70/dj1 or dj2 (Figure 1a,b). Expression levels of hsp70, dj1, and dj2 in the stable transformed cells were similar to those in heattreated RAW 264.7 cells. NO production and iNOS induction by LPS/IFN- $\gamma$ treatment were unchanged by the expression of hsp70 or hsp70/DnaJ (Figure 1c,d).

We next asked if expression of hsp70/dj1 or hsp70/dj2 would prevent NO-mediated apoptosis (Figure 2). Formation of the DNA ladder, characteristic of apoptotic cells, was observed when wild-type cells were treated with LPS/IFN- $\gamma$ (Figure 2a). This same formation was also observed in hsp70expressing cells. In contrast, cell lines expressing hsp70/dj1 or hsp70/dj2 did not show ladder formation in case of LPS/ IFN- $\gamma$ treatment. There are several subgroups in caspases, among which, caspase 3 activation is positioned downstream of the caspase activation cascade, and is thought to be the point of no return in the process of apoptosis. Caspase 3 activation was prevented by the coexpression of hsp70 and dj1 or dj2 (Figure 2b). Loss of mitochondrial membrane potential, also characteristic of apoptosis, was prevented by the coexpression of hsp70 and dj1 or dj2 (Figure 2c). Figure 2d shows morphology of cells treated with LPS/IFN- $\gamma$. When wildtype cells were treated with LPS/IFN- $\gamma$, chromatin condensation and nuclear fragmentation were seen in Hoechst dye 33258 staining. Similar apoptotic changes were observed in cells expressing hsp70 and such changes were strongly prevented by the coexpression of hsp70/dj1 or hsp70/dj2. These findings support our data obtained when doing transient expression experiments. ${ }^{29}$

As NO-induced apoptosis in RAW 264.7 cells is mediated by induction of $\mathrm{CHOP},{ }^{7}$ we determined if the induction of CHOP would be prevented by expression of hsp70/dj1 or hsp70/dj2. Figure 3 shows immunoblot analysis of nuclear extracts for CHOP. CHOP, barely detectable before LPS/IFN$\gamma$ treatment, was induced after treatment in wild-type cells and this induction was not suppressed in cells expressing hsp70/ dj1 or hsp70/dj2. Thus, the hsp70/DnaJ chaperone pairs prevent LPS/IFN- $\gamma$-induced apoptosis downstream of CHOP induction in RAW 264.7 cells.

\section{Apoptosis induced by CHOP is prevented by hsp70/DnaJ chaperone pairs in COS-7 cells}

We reported that overexpression of $\mathrm{CHOP}$ or p50ATF6 (active form of ATF6) induces apoptosis in RAW 264.7 cells and COS-7 cells. ${ }^{7}$ Expression of the transfected CHOP gene was barely detected in RAW 264.7 cells. Therefore, we used COS-7 cells, in which higher levels of expression can be obtained, in the following experiments. We examined whether hsp70/DnaJ chaperone pairs would prevent CHOP-induced apoptosis in COS-7 cells (Figure 4). Cells were cotransfected with an EGFP expression plasmid and various combinations of expression plasmids for CHOP, hsp70, dj1, dj2, and Bcl-2. When cells were transfected with only the EGFP plasmid, many cells became fluorescent (Figure 4a). Cotransfection with the CHOP plasmid markedly reduced the number of 
EGFP-positive cells, because of cell death. ${ }^{7}$ Transfection of a plasmid for hsp70, dj1, or dj2 alone did not prevent CHOPinduced apoptosis. In contrast, the reduced number of EGFPpositive cells by CHOP expression was markedly prevented by cotransfection with the plasmids for hsp70/dj1 or hsp70/ a

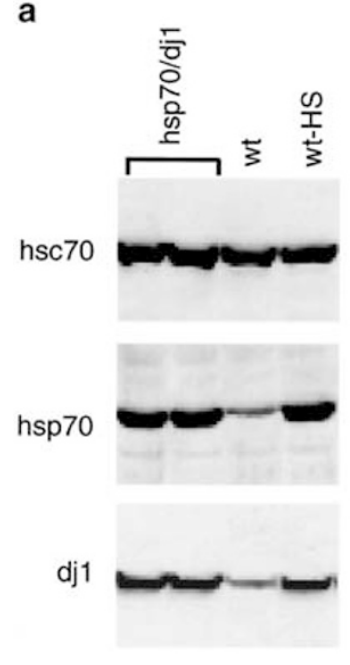

b

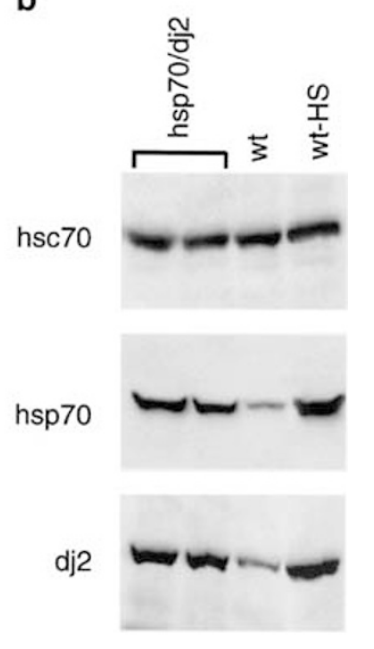

c

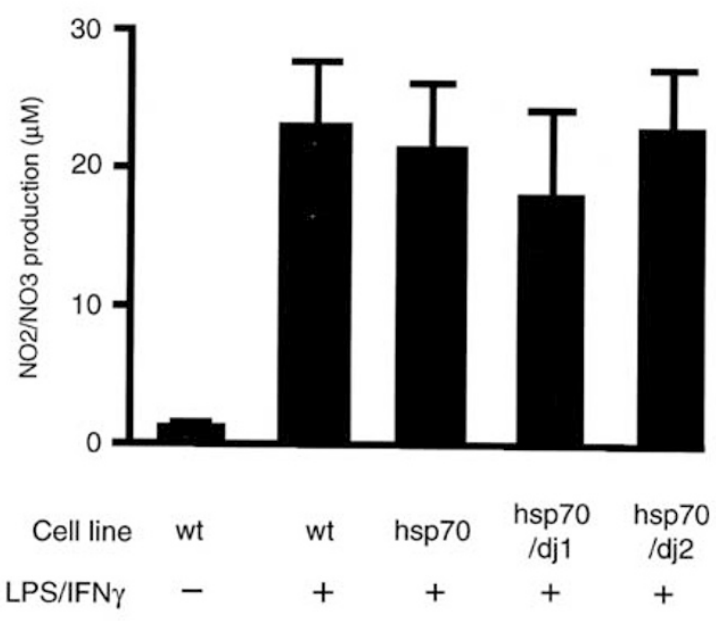

d

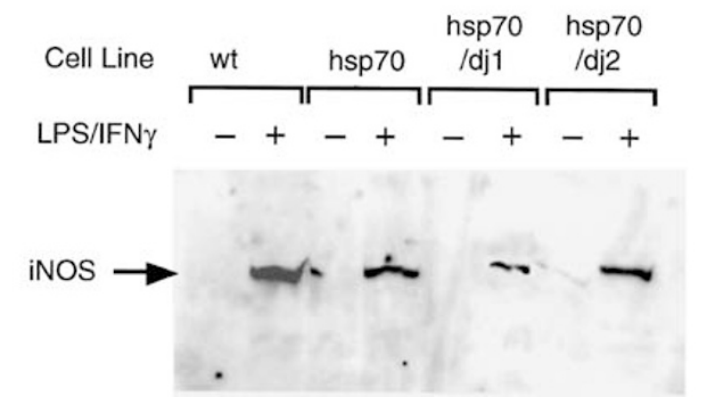

a

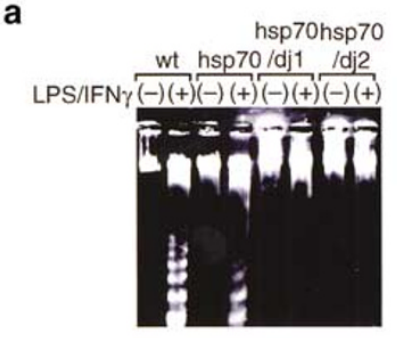

b

C

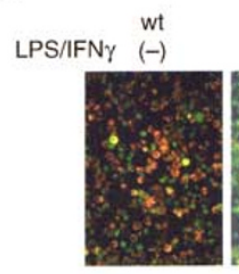

wt

$(+)$

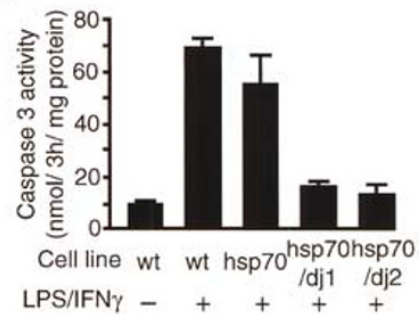

d
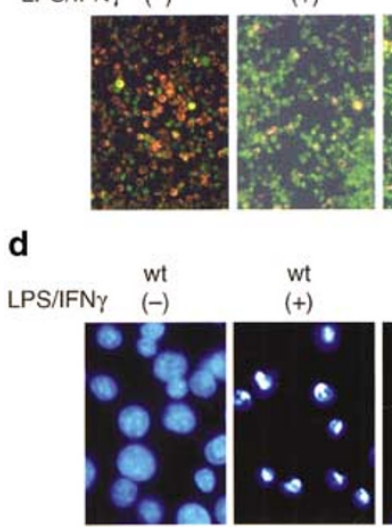

hsp70

hsp70/dj1 hsp70/dj2

$(+)$

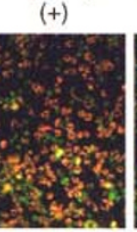

$(+)$

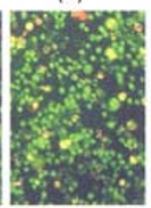

wt
$(+)$
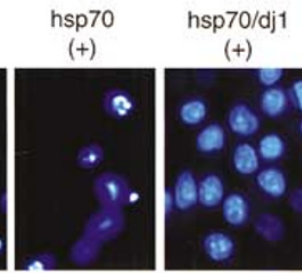

hsp70/dj2

$(+)$
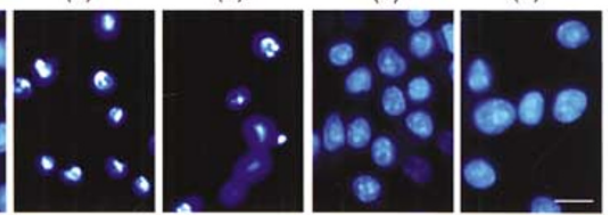

Figure 2 The hsp70/DnaJ stable transformant is resistant to NO-mediated apoptosis. (a) Wild-type and stably transformed RAW 264.7 cell lines expressing hsp70, hsp70/dj1, or hsp70/dj2 were treated with or without $150 \mu \mathrm{g} / \mathrm{ml} \mathrm{LPS}$ and $100 \mathrm{U} / \mathrm{ml} \mathrm{IFN}-\gamma$ for $12 \mathrm{~h}$ as indicated on the top. DNAs were isolated, resolved on an agarose gel, stained with ethidium bromide, and visualized for DNA fragmentation by UV transillumination. (b) Wild-type and stably transformed RAW 264.7 cell lines expressing hsp70, hsp70/dj1, or hsp70/dj2 were treated with or without $150 \mu \mathrm{g} / \mathrm{ml}$ LPS and $100 \mathrm{U} / \mathrm{ml}$ IFN $-\gamma$ for $10 \mathrm{~h}$ as indicated, extracts were prepared, and caspase 3 activity was measured, as described in Materials and Methods. The results are shown by means \pm S.D. for three dishes. (c) Wild-type and stably transformed RAW 264.7 cell lines were treated with or without $150 \mu \mathrm{g} /$ $\mathrm{ml} \mathrm{LPS}$ and $100 \mathrm{U} / \mathrm{ml} \mathrm{IFN}-\gamma$ for $10 \mathrm{~h}$ as indicated on the top, and cells were stained with a mitochondrial membrane potential-dependent dye DePsipher, as described in Materials and Methods. The red-orange fluorescent aggregates represent the dye aggregates formed depending on the mitochondrial membrane potential. If the potential is disrupted, the dye remains in its green fluorescent form in the cytosol. Original magnifications: $\times 400$. Bar, $10 \mu \mathrm{m}$. (d) Wild-type and stably transformed RAW 264.7 cell lines were treated with or without $150 \mu \mathrm{g} / \mathrm{ml}$ LPS and $100 \mathrm{U} / \mathrm{ml}$ IFN- $\gamma$ for $18 \mathrm{~h}$ as indicated. After fixation, the cells were stained with Hoechst dye 33258, and observed by fluorescence microscopy. Original magnifications: $\times 400$. Bar, $10 \mu \mathrm{m}$. A portion of the cells were detached from coverslips by treatment with LPS/IFN- $\gamma$

Figure 1 Establishment of stable RAW 264.7 cell lines expressing hsp70 and dj1 or dj2. (a) Cell extracts ( $20 \mu \mathrm{g}$ of protein) of stably transformed RAW 264.7 cell lines expressing hsp70 and dj1, wild-type RAW 264.7 cell line (wt) and RAW 264.7 cells treated with heat shock (wt-HS) were subjected to immunoblot analysis for hsc70, hsp70, and dj1 proteins. (b) Cell extracts ( $20 \mu \mathrm{g}$ of protein) of stably transformed RAW 264.7 cell lines expressing hsp70 and dj2, wild-type RAW 264.7 cell line and RAW 264.7 cells treated with heat shock (wt-HS) were subjected to immunoblot analysis for hsc70, hsp70, and dj2 proteins. (c) Wild type and stable transformed RAW 264.7 cell lines expressing hsp70, stably transformed RAW 264.7 cell lines expressing hsp70/dj1 or hsp70/dj2 were treated with or without $150 \mu \mathrm{g} / \mathrm{ml}$ LPS and $100 \mathrm{U} / \mathrm{ml} \mathrm{IFN}-\gamma$ for $10 \mathrm{~h}$. Then, $\mathrm{NO}_{2}^{-}$ plus $\mathrm{NO}_{3}^{-}$in the medium was measured. The results are shown as means \pm S.D. for three dishes. (d) Wild-type and stably transformed RAW 264.7 cell lines expressing hsp70, hsp70/dj1, or hsp70/dj2 were treated with or without $150 \mu \mathrm{g} /$ $\mathrm{ml}$ LPS and $100 \mathrm{U} / \mathrm{ml} \mathrm{IFN}-\gamma$ for $10 \mathrm{~h}$ as indicated on the top, and cell extracts ( $50 \mu \mathrm{g}$ of protein) were subjected to immunoblot analysis for inducible type NO synthase (iNOS) 


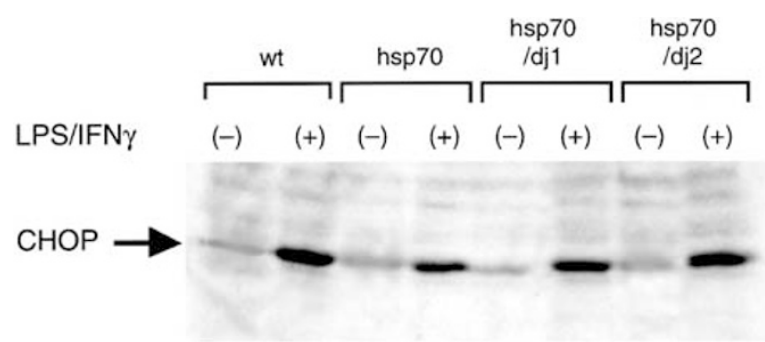

Figure 3 Expression of hsp70/DnaJ chaperone pair does not prevent NOinduced CHOP induction. Wild-type and stably transformed RAW 264.7 cell lines expressing hsp70, hsp70/dj1, or hsp70/dj2 were treated with or without $150 \mu \mathrm{g} /$

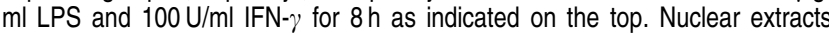
(30 $\mu \mathrm{g}$ of protein) were subjected to immunoblot analysis for CHOP protein

a
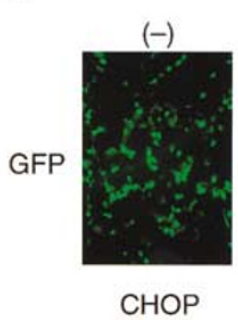

dj2

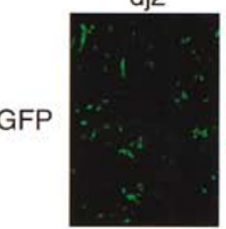

b

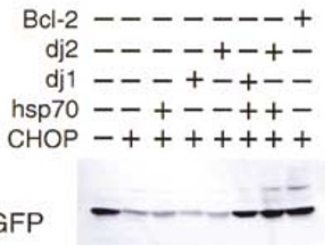

GAPDH

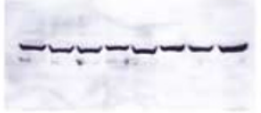

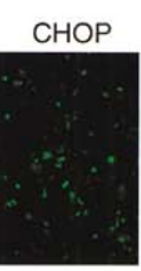

CHOP
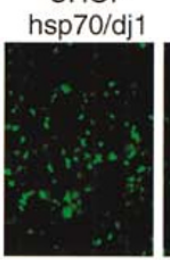

C

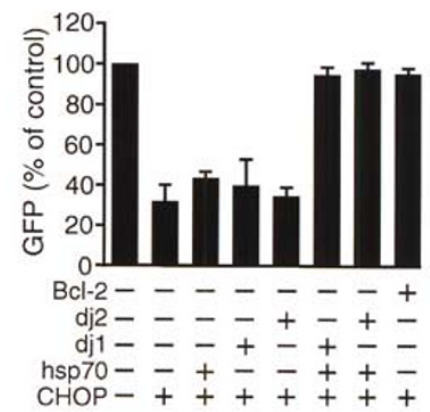

Figure 4 Coexpression of hsp70, and dj1 or dj2 protected COS-7 cells from CHOP-induced apoptosis. (a) Cells were cotransfected with an EGFP expression plasmid and various combinations of expression plasmids for CHOP, hsp70, dj1, $\mathrm{dj} 2$, or Bcl-2 as indicated on the top. After $24 \mathrm{~h}$, cells were observed using fluorescence microscopy. Original magnifications: $\times 200$. Bars, $10 \mu \mathrm{m}$. (b) Cells were treated as in (a) and cell extracts ( $20 \mu \mathrm{g}$ of protein) were subjected to immunoblot analysis for GFP and glyceraldehyde 3-phosphate dehydrogenase (GAPDH). (c) The results in (b) were quantified, and are shown by means \pm S.D. for three dishes

dj2. Transfection with a plasmid, for an antiapoptotic protein $\mathrm{Bcl}-2$, also prevented the reduction in numbers of EGFPpositive cells induced by CHOP. This result shows CHOP induce apoptosis through mitochondria pathway. This finding agrees with our previous observations that hsp70/DnaJ chaperone pairs prevent NO-induced and CHOP-mediated apoptosis upstream of cytochrome $c$ release from the

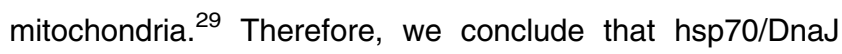
chaperone pairs exert their antiapoptotic effects downstream of $\mathrm{CHOP}$ induction, and upstream of cytochrome $c$ release from mitochondria. Expression of EGFP was quantified by immunoblot analysis, and the results are shown in Figure 4b, c. Glyceraldehyde 3-phosphate dehydrogenase (GAPDH) was also measured as control.

\section{Apoptosis induced by the active form of ATF6 is prevented by hsp70/DnaJ chaperone pairs in COS-7 cells}

ATF6 exists constitutively as a transmembrane protein p90ATF6 in the ER under nonstressed conditions. ${ }^{31}$ ER stress induces proteolysis of p90ATF6 and releases a soluble transcription factor p50ATF6 (active form) which is transported into the nucleus, binds to the ER stress-responsive element (ERSE) of the CHOP and ER chaperone genes, and activates their transcription. ATF6 is activated in LPS/IFN- $\gamma$ induced apoptosis and functions as a transactivator of the CHOP gene. ${ }^{7}$ Therefore, we asked if the apoptosis induced by the overexpression of p50ATF6 would be prevented by transfection with expression plasmids for hsp70/dj1 or hsp70/dj2 in COS-7 cells (Figure 5). When cells were cotransfected with the EGFP plasmid and the plasmid for p50ATF6, the amount of EGFP was reduced because of cell death, and this reduction was prevented by transfection with the plasmids for hsp70/dj1 or hsp70/dj2. Transfection with the plasmid for hsp70, dj1, or dj2 alone had little effect. Transfection with a plasmid for $\mathrm{Bcl}-2$ prevented the p50ATF6-induced reduction of EGFP, suggesting that this cell death is mediated by the mitochondrial apoptosis pathway.

\section{ATPase domain and the C-terminal portion of hsp70, and farnesylation of $\mathrm{dj} 2$ are necessary for antiapoptotic effect of hsp70/dj2 pair in CHOP-induced apoptosis}

ATP which binds the $\mathrm{N}$-terminal domain of hsp70 drives conformational changes in the C-terminal peptide binding domain that alters its affinity for substrates. ${ }^{23}$ The ATP-bound state of hsp70 shows low affinity and fast exchange rates for substrates, whereas the ADP-bound state shows high affinity and slow exchange rates for substrates. Therefore, the ATPase domain of hsp70 is crucial for its chaperone activity. On the other hand, the C-terminal EEVD motif of hsp70 is responsible for binding with co-chaperone hop and chip. ${ }^{32,33}$

We investigated whether the ATPase domain and Cterminal motif are essential for antiapoptotic function of hsp70 (Figure 6). We constructed expression plasmids for hsp70 mutant forms, lacking the ATPase domain or the Cterminal EEVD motif. Plasmids for these hsp70 mutants in combination with the dj2 expression plasmid, were not effective in preventing CHOP-induced apoptosis (Figure 6a, b). Therefore, ATPase activity and the C-terminal EEVD motif of hsp70 are essential for its antiapoptotic activity. Figure 6c shows the expression of transfected genes. 


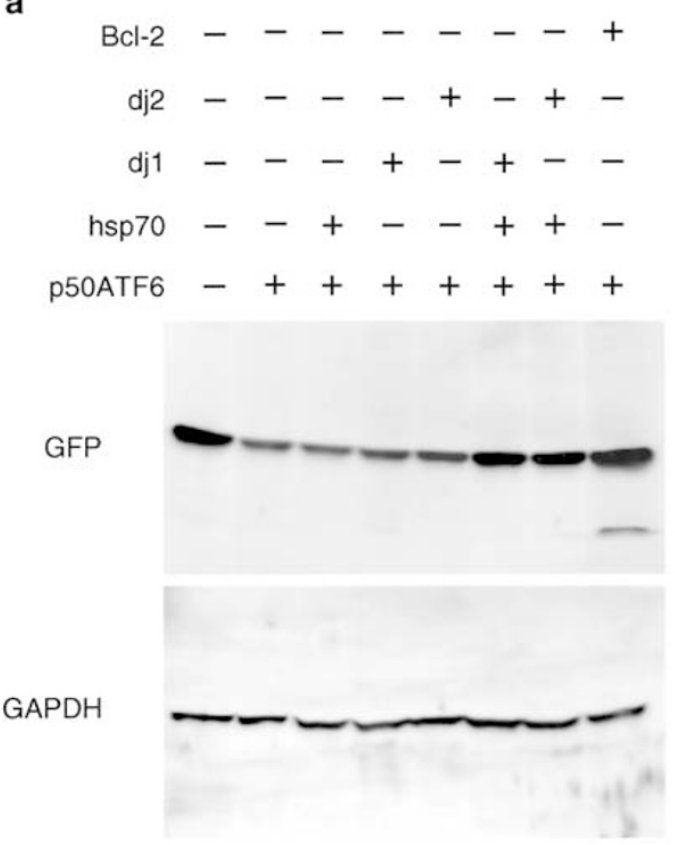

b

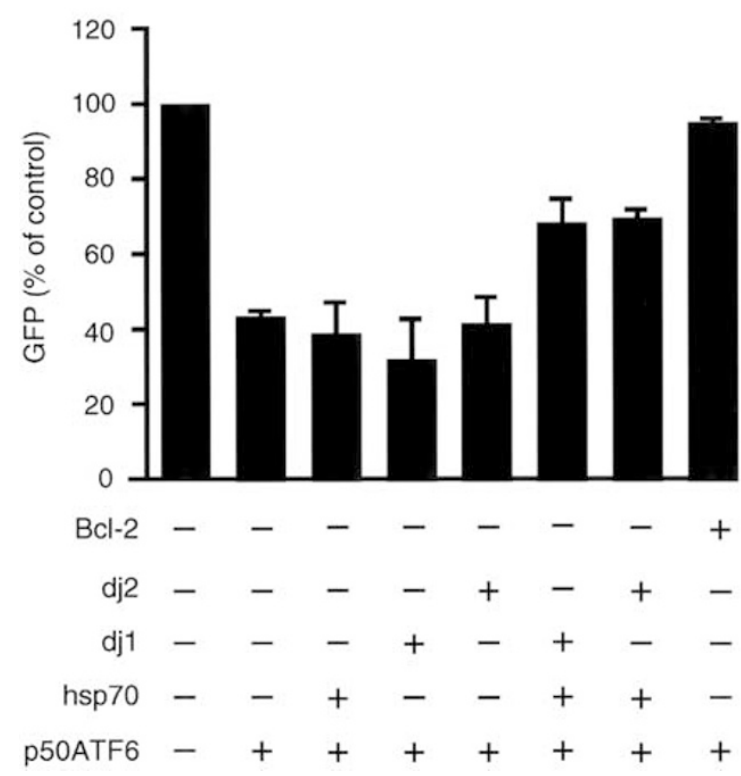

Figure 5 Coexpression of hsp70, and dj1 or dj2 protected COS-7 cells from p50ATF6-induced apoptosis. (a) Cells were cotransfected with an EGFP expression plasmid and various combinations of expression plasmids for p50ATF6, hsp70, dj1, dj2, and Bcl-2 as indicated on the top. After $24 \mathrm{~h}$, cell extracts ( $20 \mu \mathrm{g}$ of protein) were subjected to immunoblot analysis for GFP and glyceraldehyde 3-phosphate dehydrogenase (GAPDH). (b) The results in (a) were quantified, and are shown by means \pm S.D. for three dishes

dj2 has the CaaX prenylation motif at its C-terminal and undergoes farnesylation. ${ }^{34}$ We asked whether this modification is crucial for anti-apoptotic effect of dj2 (Figure 7). We constructed an expression plasmid for unprenylated dj2 mutant C394S, in which cysteine of the 'CaaX box' was mutated to serine. Cotransfection with this mutant plasmid in combination with hsp70 was partly, but not fully effective in a

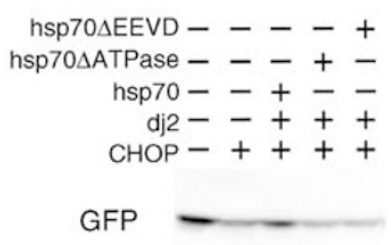

b

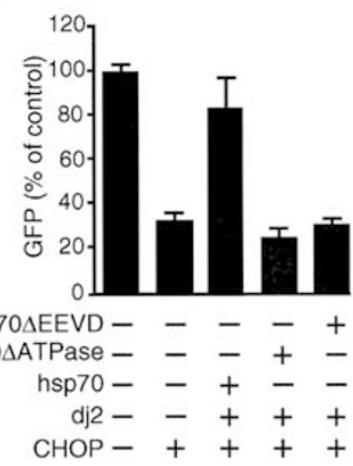

C

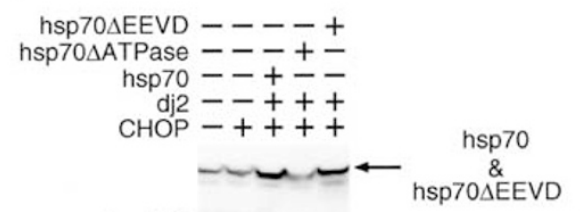

hsp70

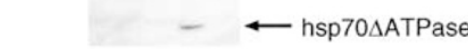

dj2

CHOP

Figure 6 Mutant hsp70 does not protect COS-7 cells from CHOP-induced apoptosis. (a) Cells were cotransfected with an EGFP expression plasmid and various combinations of expression plasmids for CHOP, wild-type hsp70, ATPase domain-deleted hsp70 (hsp70 $\triangle$ ATPase), C-terminal sequence EEVDdeleted hsp70 (hsp70 $\triangle E E V D$ ) or dj2 as indicated on the top. After $24 \mathrm{~h}$, cell extracts ( $20 \mu \mathrm{g}$ of protein) were subjected to immunoblot analysis for GFP and glyceraldehyde 3-phosphate dehydrogenase (GAPDH). (b) The results in (a) were quantified, and are shown by means \pm S.D. for three dishes. (c) Cells were treated as in (a), and cell extracts $(20 \mu \mathrm{g}$ of protein) were subjected to immunoblot analysis for hsp70, dj2, and CHOP

preventing the CHOP-induced reduction of EGFP expression (Figure 7a, b). This indicates that prenylation is important, but not essential in the antiapoptotic effect of dj2. Figure $7 \mathrm{c}$ shows the expression of transfected genes.

\section{CHOP induces translocation of Bax from the cytosol to the mitochondria in NO-mediated apoptosis, and this translocation is prevented by the hsp70/dj2 chaperone pair}

Bax is a proapoptotic $\mathrm{Bcl}-2$ family protein. ${ }^{35}$ Translocation of Bax from the cytosol to the mitochondria occurs in the apoptosis induced by various stresses and agents, and is thought to cause cytochrome $c$ release from mitochondria. Therefore, we asked whether translocation of Bax takes place in LPS/IFN- $\gamma$-induced apoptosis, and whether this translocation is prevented by the expression of hsp70/dj2 chaperone pair (Figure 8a). After LPS/IFN- $\gamma$ treatment, wild-type and hsp70/dj2-transformed RAW 264.7 cells were fractionated into the soluble fraction and the particulate fraction containing mitochondria, using digitonin, and immunoblot analysis was performed. In both wild-type and transformed cells, 
a

$$
\begin{array}{r}
\mathrm{dj} 2---+++ \\
\mathrm{dj} 2 \mathrm{~m}--+-+- \\
\mathrm{hsp} 70--+-++ \\
\mathrm{CHOP}-+++++ \\
\mathrm{GFP}
\end{array}
$$

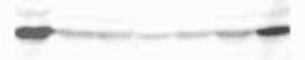

GAPDH

C

b
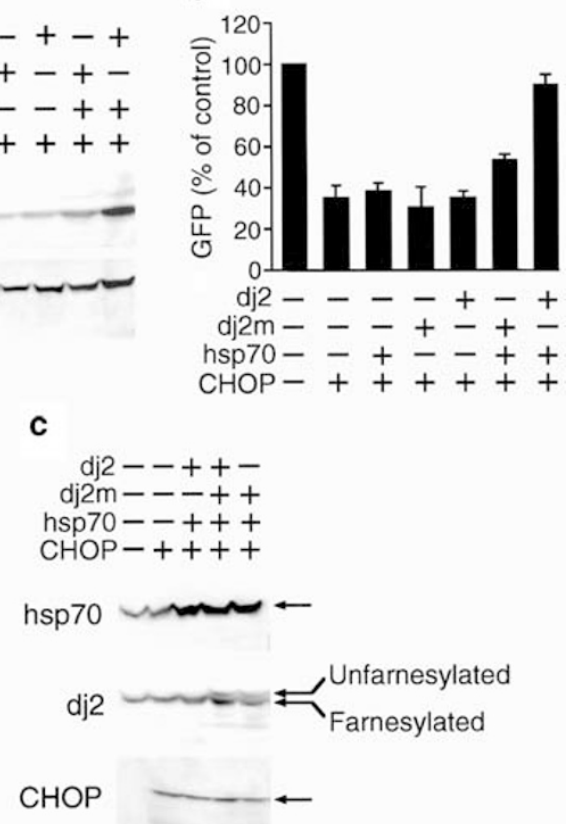

Figure 7 Farnesylation of dj2 is important for antiapoptotic effect in $\mathrm{CHOP}$ induced apoptosis. (a) COS-7 cells were cotransfected with an EGFP expression plasmid and various combinations of expression plasmids for $\mathrm{CHOP}, \mathrm{hsp} 70$, dj2, or unfarnesylated mutant form of dj2 (dj2 $\mathrm{m}$ ) as indicated on the top. After $24 \mathrm{~h}$, cell extracts (20 $\mu \mathrm{g}$ of protein) were subjected to immunoblot analysis for GFP and glyceraldehyde 3-phosphate dehydrogenase (GAPDH). (b) The results in (a) were quantified, and are shown by means \pm S.D. for three dishes. (c) COS-7 cells were treated as in (a), and cell extracts ( $20 \mu \mathrm{g}$ of protein) were subjected to immunoblot analysis for hsp70, dj2, and CHOP

cytochrome $c$ was recovered exclusively in the particulate fraction, and Bax was recovered exclusively in the soluble fraction before the treatment. When wild-type cells were treated with LPS/IFN- $\gamma$, cytochrome $c$ was recovered exclusively in the soluble fraction, whereas Bax was recovered mostly in the particulate fraction. In contrast, when transformed cells were treated with LPS/IFN- $\gamma$, cytochrome $c$ was almost completely recovered in the particulate fraction, and Bax was recovered mostly in the soluble fraction. Under these conditions, a mitochondrial matrix protein hsp60 was recovered exclusively in the particulate fraction, whereas a cytosolic protein GAPDH was recovered exclusively in the soluble fraction. Therefore, we conclude that translocation of Bax in LPS/IFN- $\gamma$-induced apoptosis is prevented by the hsp70/dj2 chaperone pair in RAW 264.7 cells. This was confirmed by double immunostaining of RAW 264.7 cells (Figure 8b). Particulate structures in the cytoplasm were stained with an hsp60 antibody, this reflects the mitochondria localization of this protein. In untreated wild-type cells, the cytoplasm was diffusely positive for Bax immunostaining, whereas particulate structures similar to those positive for hsp60 immunostaining were observed in the cytoplasm after LPS/IFN- $\gamma$ treatment, thus indicating translocation of Bax to the mitochondria. In contrast, when transformed cells were treated with LPS/IFN- $\gamma$, the cytoplasm was still diffusely positive for Bax immunostaining, thereby indicating prevention of Bax translocation by hsp70/dj2.
We next asked whether Bax translocation to mitochondria by $\mathrm{NO}$ is dependent on $\mathrm{CHOP}$, using primary-cultured peritoneal macrophages from CHOP knockout mice (Figure 8c). As shown in Figure 8b, Bax was localized in cytosol under nonapoptotic conditions. When apoptosisinducing stress or reagent is added, Bax conformation change to the proapoptotic state takes place and Bax is translocated to mitochondria. ${ }^{36}$ Bax antibody $(\mathrm{N}-20)$ is specific to the proapoptotic state, ${ }^{36}$ and Bax antibody $(\Delta 21)$ reacts with any conformation of Bax. When untreated peritoneal macrophages from wild-type or CHOP knockout mice were immunostained with Bax antibodies, the cytoplasm was diffusely stained with the $\Delta 21$ antibody, whereas no immunofluorescence was detected with the $\mathrm{N}-20$ antibody. In contrast, when peritoneal macrophages from wild-type mice were treated with SNAP $(1.5 \mathrm{mM})$ for $10 \mathrm{~h}$, chromatin condensation was seen in Hoechst dye 33258 staining, indicating apoptosis. In Bax immunostaining using the $\Delta 21$ antibody or $\mathrm{N}-20$ antibody, particulate structures were observed in the cytoplasm, indicating translocation of Bax to mitochondria. Positive staining with the $\mathrm{N}-20$ antibody shows the conformation change of Bax. In contrast, when peritoneal macrophages from CHOP knockout mice were treated with SNAP for $10 \mathrm{~h}$, apoptotic change was barely detected in Hoechst dye 33258 staining. The cytoplasm was diffusely stained with the $\Delta 21$ antibody and little immunostaining was observed with the $\mathrm{N}-20$ antibody. These results show that translocation of Bax to mitochondria and conformation change of Bax induced by NO is CHOP dependent.

We then asked whether CHOP-induced apoptosis is dependent on Bax (Figure 8d-f). Hela cells were cotransfected with an EGFP expression plasmid, an inducible CHOP expression plasmid and siRNA for Bax knock down. At $48 \mathrm{~h}$ after transfection, IPTG was added to induce CHOP expression, and cells were incubated further for $24 \mathrm{~h}$. When CHOP was induced, the number of EGFP-positive cells was reduced indicating apoptosis. This reduction was not prevented by mouse Bax sequence-specific siRNA (RNAiMBax), used as control. In contrast, when human Bax sequence-specific siRNA (RNAiHBax), was transfected, reduction of EGFPpositive cells were prevented, same as in the case of hsp70/ dj2 chaperone pair expression. Expression of Bax protein, which did not change by control siRNA (RNAiMBax), was reduced by transfection of human Bax sequence-specific siRNA (RNAiHBax) (Figure 8g). Expression of CHOP protein, which was not detected in control cells, was induced by IPTG addition, and did not change by control or human Bax-specific siRNA. These results show that CHOP-induced apoptosis is dependent on Bax.

We next asked whether the translocation of Bax is induced by CHOP expression, and whether this translocation is prevented by the hsp70/dj2 chaperone pair in COS-7 cells (Figure 9a, b). Cells were cotransfected with an EGFP-Bax fusion plasmid and various combinations of plasmids for CHOP, hsp70, dj1, dj2, and Bcl-2. When cells were transfected with an EGFP-Bax plasmid alone, cells were diffusely positive for EGFP. In contrast, when COS-7 cells were cotransfected with plasmids for EGFP-Bax and CHOP, small particulate structures in the cytoplasm were positive for EGFP, thus reflecting the mitochondrial localization of Bax. In 
a

$$
\text { LPS/IFN } \gamma \frac{\text { wt }}{\text { Bax }}
$$

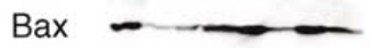

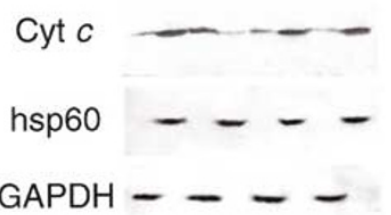

b

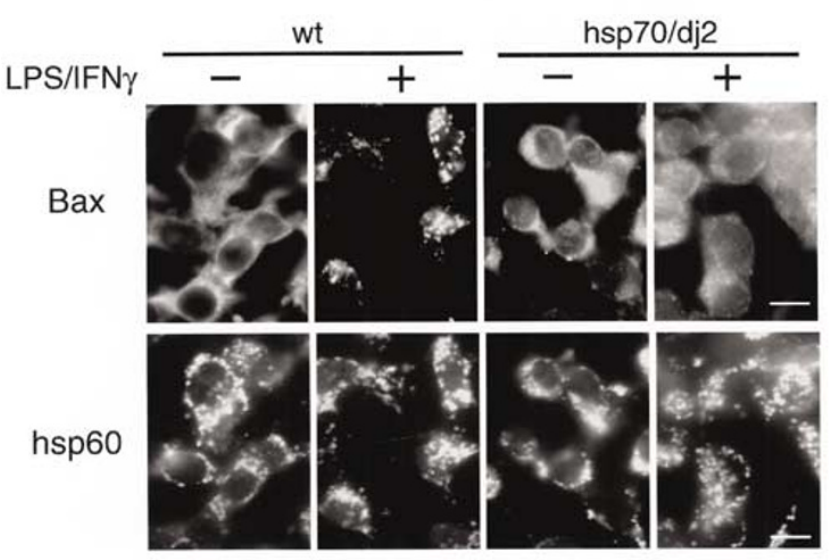

C

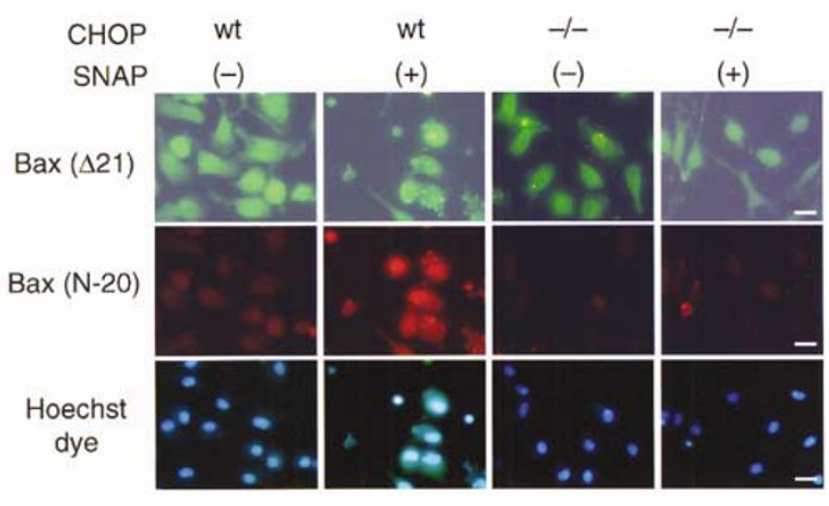

d

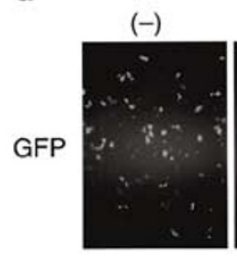

CHOP

CHOP

CHOP

CHOP RNAiMBax RNAiHBax hsp70/dj2

e
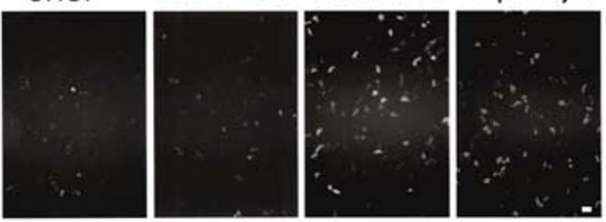

f

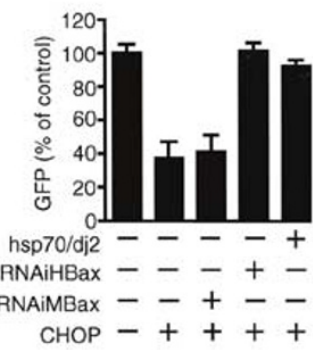

g

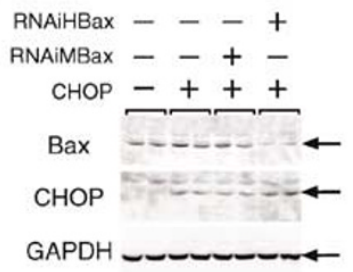

Figure 8 hsp70/dj2 chaperone pair prevent NO and CHOP-induced Bax translocation. (a) Wild-type and hsp70/dj2-stable transformant RAW 264.7 cell lines were treated with LPS $(150 \mu \mathrm{g} / \mathrm{ml})$ plus IFN $\gamma(100 \mathrm{U} / \mathrm{ml})$ for $10 \mathrm{~h}$ and fractionated into the soluble fraction $(\mathrm{S})$ and the particulate fraction $(\mathrm{P})$, as described under Materials and Methods. Distribution of total protein in the soluble fraction and the particulate fraction was 65 and $35 \%$, respectively. The fractions (10 $\mu \mathrm{g}$ of protein) were subjected to immunoblot analysis for Bax, cytochrome $c$ (Cyt c), hsp60, and glyceraldehyde 3-phosphate dehydrogenase (GAPDH). (b) Wild-type and hsp70/dj2-stable transformant RAW 264.7 cell lines were treated as in (a). After fixation, the cells were double-immunostained with antibodies against Bax and mitochondria chaperone hsp60 as described under Materials and Methods. Original magnifications: $\times 1000$. Bars, $10 \mu \mathrm{m}$. (c) Peritoneal macrophages were prepared from wild-type (wt) and CHOP knockout mice (-l-). Cells were treated with $1.5 \mathrm{mM}$ NO-donor SNAP for $10 \mathrm{~h}$. The cells were then fixed and double-immunostained with a monoclonal antibody against Bax lacking the carboxy terminal 21 amino-acid residues $(\operatorname{Bax}(\Delta 21))$ or a polyclonal antibody against the N-terminal portion of Bax (Bax (N20)), stained with Hoechst dye 33258 and observed by fluorescence microscopy. Original magnifications: $\times 400$. Bars, $10 \mu \mathrm{m}$. (d) Hela cells were cotransfected with an EGFP expression plasmid, a CHOP-inducible expression plasmid, and a p3'SS lac repressor-expressing vector. siRNAs for mouse Bax (RNAiMBax) or human Bax (RNAiHBax), and expression plasmids for hsp70 and dj2 were also cotransfected as indicated on the top. After $48 \mathrm{~h}$, IPTG (5 mM) was added to induce CHOP as indicated on the top. The cells were further cultured for $24 \mathrm{~h}$, and observed by fluorescence microscopy. Original magnifications: $\times 200$. Bar, $10 \mu \mathrm{m}$. (e) Hela cells were treated as in (d), and cell extracts (20 $\mu \mathrm{g}$ of protein) were subjected to immunoblot analysis for GFP and glyceraldehyde 3-phosphate dehydrogenase (GAPDH). (f) The results in (e) were quantified, and are shown by means \pm S.D. for three dishes. (g) Hela cells were treated as in (d), and cell extracts (60 $\mu \mathrm{g}$ of protein) were subjected to immunoblot analysis for Bax, $\mathrm{CHOP}$, and GAPDH

addition, cells became condensed and round-shaped, reflecting apoptotic changes. Cotransfection with a plasmid for hsp70, dj1, or dj2 alone did not affect these changes in EGFP localization and of the cell shape induced by CHOP. These changes were canceled out by cotransfection with plasmids for hsp70/dj1 or hsp70/dj2. Expression of Bcl-2 was also 
effective. This was confirmed by cell fractionation (Figure 9b). COS-7 cells were fractionated into the soluble fraction containing cytosol and the particulate fraction containing mitochondria, and immunoblot analysis was performed. When EGFP-Bax alone was expressed, it was recovered exclusively in the soluble fraction. When EGFP-Bax and CHOP were coexpressed, EGFP-Bax was recovered in the particulate fraction, and this translocation of EGFP-Bax by CHOP was prevented by coexpression of hsp70/dj2.

Translocation of EGFP-Bax from the cytosol to the mitochondria was also confirmed by cotransfection with a plasmid for another fluorescent protein DsRed containing

mitochondrial targeting signal (DsRed-Mit) (Figure 9c). When COS-7 cells were cotransfected with plasmids for DsRed-Mit and EGFP, DsRed fluorescence was detected in small particulate structures in the cytoplasm, thereby reflecting the mitochondrial localization of DsRed. EGFP was diffuse in the cytoplasm. On the other hand, EGFP-Bcl-2 fusion protein was detected in mitochondria. EGFP-Bax was detected in the cytoplasm without CHOP. When the CHOP expression plasmid was cotransfected, EGFP-Bax was colocalized to mitochondrial DsRed. Therefore, CHOP induces the translocation of Bax from the cytosol to the mitochondria and this translocation is prevented by the hsp70/dj2 chaperone pair.

a

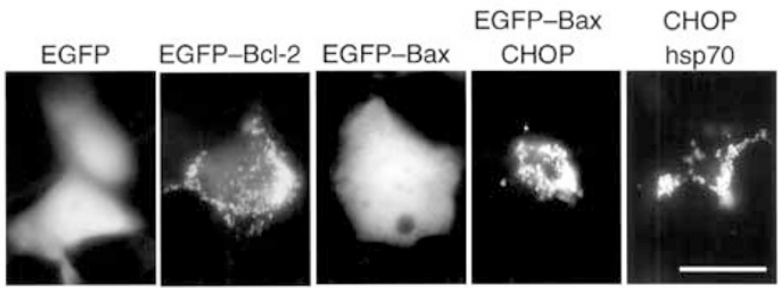

EGFP-Bax, CHOP

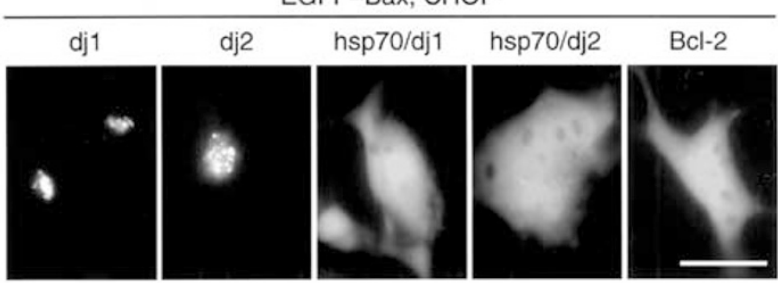

b

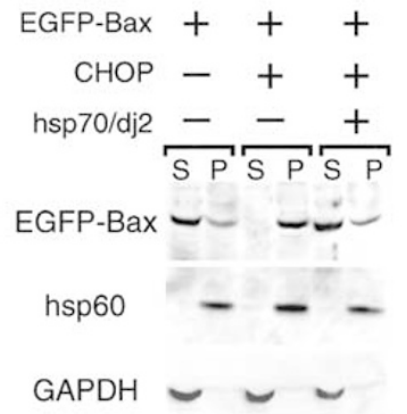

C

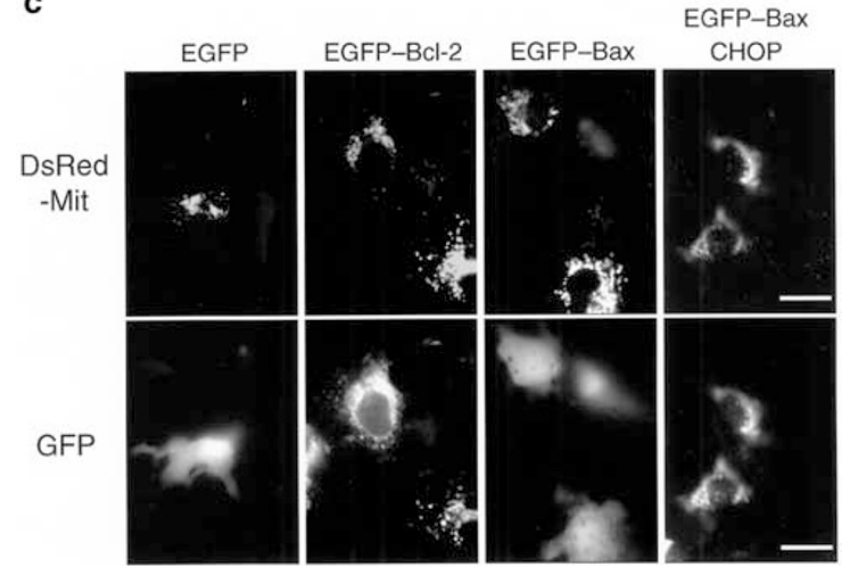

\section{Bax interacts with hsp70 and dj1/dj2}

We next asked whether Bax interacts with hsp70 and DnaJ chaperones (Figure 10a). RAW 264.7 cells were heat treated to induce hsp70, dj1, and dj2. This treatment protects RAW 264.7 cells from NO-induced apoptosis. ${ }^{29}$ Then cell extracts were subjected to immunoprecipitation with an anti-Bax antibody. When we used extracts of heat-treated cells, hsp70, hsc70, dj1, and dj2 were co-precipitated. When extracts from nontreated RAW 264.7 cells were used, the precipitated hsp70, dj1, and dj2 were reduced, reflecting low expression of chaperones in untreated cells (Figure 1). While expression of hsc70 was not changed by heat treatment (Figure 1), precipitation of hsc70 in extracts from nontreated cells was a little increased. This is probably because of the lack of competition with hsp70 for binding with Bax in nontreated cell extract. These results indicate that Bax interacts with hsp70, dj1, and dj2 in heat-treated cells, and suggest that this association prevents Bax translocation to the mitochondria. In nontreated cells, hsc70 interacts with Bax, but this is not enough for preventing the translocation of Bax.

Binding of hsp70 mutants with Bax is shown in Figure $10 \mathrm{~b}$. When hsp70 and dj2 were coexpressed with Bax in COS-7 cells, both hsp70 and dj2 were co-precipitated with Bax. In contrast, when ATPase domain-deleted hsp70 was expressed, this mutant was not co-precipitated with Bax and dj2. We speculated that under these conditions dj2 was coprecipitated with endogenous hsp70 and hsc70, together with Bax. These results together with the results in Figure 6 show

Figure 9 Coexpression of hsp70, and dj1 or dj2 protected CHOP-induced EGFP-Bax translocation to mitochondria in COS-7 cells. (a) Cells were transfected with various combinations of expression plasmids for EGFP, EGFP. Bcl-2, EGFP-Bax, CHOP, hsp70, dj1, dj2, or Bcl-2 as indicated on the top. After $24 \mathrm{~h}$, cells were observed by fluorescence microscopy. Original magnifications: $\times 1000$. Bars, $10 \mu \mathrm{m}$. (b) Cells were transfected with an EGFP-Bax expression plasmid and indicated combinations of expression plasmids for CHOP, hsp70, or di2. After $24 \mathrm{~h}$, cells were fractionated into the soluble fraction $(S)$ and the particulate fraction $(\mathrm{P})$, as described under Materials and Methods. Distribution of total protein in the soluble fraction and the particulate fraction was 62 and $38 \%$, respectively. The fractions (10 $\mu \mathrm{g}$ of protein) were subjected to immunoblot analysis for Bax (EGFP-Bax), hsp60 and glyceraldehyde 3phosphate dehydrogenase (GAPDH). (c) Cells were cotransfected with an DsRed-Mit expression plasmid and an expression plasmid for EGFP, EGFP$\mathrm{Bcl}$-2, EGFP-Bax, or EGFP-Bax plus CHOP. After $24 \mathrm{~h}$, cells were observed by fluorescence microscopy. DsRed images (upper panels) and EGFP images (lower panels) of the same fields are shown. Original magnifications: $\times 1000$. Bars, $10 \mu \mathrm{m}$ 
a

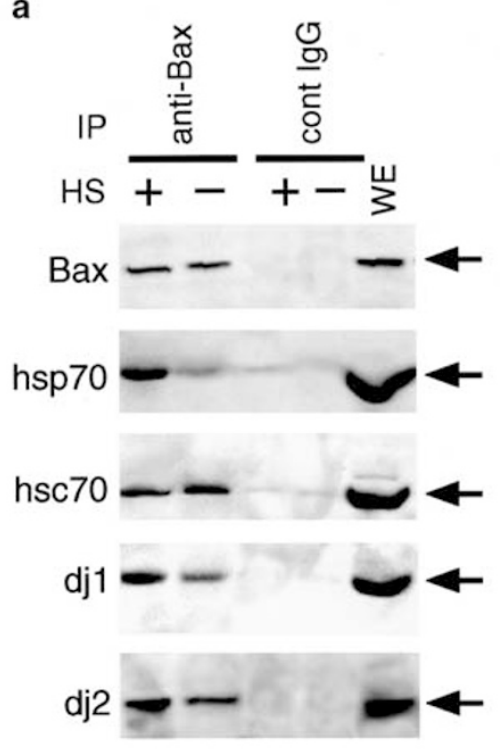

b

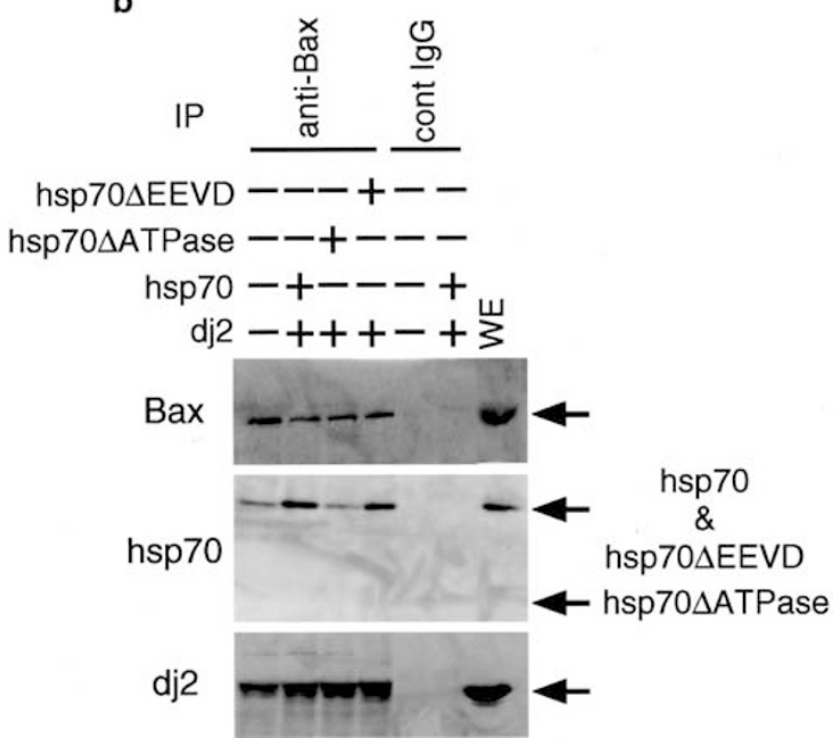

Figure 10 Bax interacts with $\mathrm{hsp} 70$, dj1, and dj2. (a) RAW 264.7 cells were heat treated at $42^{\circ} \mathrm{C}$ for $2 \mathrm{~h}$ and returned to $37^{\circ} \mathrm{C}$ for $6 \mathrm{~h}(\mathrm{HS})$. Cell extracts (300 $\mu \mathrm{g}$ of protein) were subjected to immunoprecipitation using an anti-Bax polyclonal antibody or control $\lg G$ (nonimmune rabbit $\lg G$ ) as described in Materials and Methods. The immunoprecipitates were subjected to immunoblot analysis for the indicated proteins. WE, whole cell extract of heat-treated RAW 264.7 cells $(50 \mu \mathrm{g}$ of protein). (b) COS-7 cells were transfected with a Bax expression plasmid and various combinations of expression plasmids for wildtype hsp70, ATPase domain-deleted hsp70 (hsp70 $A$ ATPase), C-terminal sequence EEVD deleted hsp70 (hsp70 $\triangle E E V D$ ) or dj2 as indicated on the top. After $24 \mathrm{~h}$, cell extracts ( $300 \mu \mathrm{g}$ of protein) were subjected to immunoprecipitation using an anti-Bax polyclonal antibody or control lgG (cont lgG, nonimmune rabbit $\lg G$ ) as described in Materials and Methods. The immunoprecipitates were subjected to immunoblot analysis for the indicated proteins. WE, whole cell extract of COS-7 cells (30 $\mu \mathrm{g}$ of protein) transfected with expression plasmids for Bax, hsp70, and dj2

that the ATPase domain of hsp70 is necessary both for antiapoptotic effect and binding with Bax. On the other hand, the C-terminal EEVD motif is necessary for antiapoptotic effect, but not for binding with Bax. As already mentioned, the
C-terminal EEVD motif of hsp70 is responsible for binding with co-chaperones including hop and chip. Therefore, we speculate that hop and chip are involved, not in the binding with Bax, but the following antiapoptotic events.

\section{Discussion}

\section{CHOP induce apoptosis through Bax translocation to mitochondria in NO-mediated apoptosis in macrophages}

NO induces apoptosis through the ER stress pathway involving $\mathrm{CHOP}$ induction in some cell types. ${ }^{6,7}$ We previously showed that pancreatic islets and peritoneal macrophages from $\mathrm{CHOP}$-knockout mice are more resistant to NO-induced apoptosis. ${ }^{5,7}$ However, the precise mechanism of CHOPinduced apoptosis was not fully elucidated. Here we found that $\mathrm{CHOP}$ induce apoptosis through Bax translocation from cytosol to mitochondria. We also showed that overexpression of $\mathrm{Bcl}-2$ prevents $\mathrm{CHOP}$-induced apoptosis. This agrees well with our previous findings that NO induces apoptosis through a mechanism involving cytochrome $c$ release from mitochondria. ${ }^{29} \mathrm{Bcl}-2$ family members are key regulators that control release of cytochrome $c$ and other apoptosis-promoting factors from mitochondria. ${ }^{35,37,38} \mathrm{Bcl}-2$ family proteins are separated into three groups. Group I members including $\mathrm{Bcl}-2$ and $\mathrm{Bcl}-\mathrm{X}_{\mathrm{L}}$, have four conserved $\mathrm{Bcl}-2$ homology $(\mathrm{BH})$ domains (BH1-BH4), and antiapoptotic function. Group II members including Bax and Bak, lack the N-terminal BH4 domain, and function as proapoptotic molecules. Group III members including Bid and Bim, contain only a single $\mathrm{BH} 3$ domain, and function as proapoptotic molecules.

Bax is mainly located in the cytosol under nonapoptotic conditions and translocates to the mitochondria in response to apoptotic stimuli. Once the BH3-only proteins bind to the mitochondria, they cooperate with other proapoptotic Bcl-2 family proteins to induce the release of apoptogenic proteins. The proapoptotic group II Bcl-2 family members, such as Bax and Bak, are likely to be mediators for BH3-only proteins. The important role of these proteins in apoptosis was demonstrated using Bax and Bak double knockout mice. ${ }^{39}$ MEF cells lacking Bax and Bak are resistant to multiple apoptotic stimuli, including ultraviolet irradiation, growth factor deprivation, treatment with a variety of drugs, and the overexpression of BH3-only proteins tBid, Bim, and Bad. Concurrent with the translocation of the $\mathrm{BH} 3$-only proteins to the mitochondria, Bax undergoes conformational changes and oligomerization, and is inserted into the outer membrane of the mitochondria. ${ }^{36,40,41}$ Enforced dimerization of Bax results in translocation to the mitochondria and apoptosis. ${ }^{42}$ The oligomerized Bax and Bak may form a pore for apoptogenic proteins, or may interact with the mitochondrial outer membrane voltagedependent anion channel (VDAC) to induce a change of VDAC permeability to allow apoptogenic proteins to pass through. ${ }^{43}$ However, the mechanism of Bax-induced cytochrome $c$ release from the mitochondria is not fully understood.

Other remaining questions to be clarified are what drives the oligomerization of Bax and its insertion. In this study, we showed that excess NO and CHOP expression induces Bax 
translocation to the mitochondria. NO and NO-related species were reported to induce apoptosis through activation of p38 and JNK MAP kinase. ${ }^{4,44,45}$ JNK activation induces cytochrome $c$ release from the mitochondria. The molecular mechanism of this release is unclear, but may involve regulation of expression and phosphorylation of the $\mathrm{Bcl}-2$ family proteins. It was shown that cells lacking both Bax and Bak become resistant to the apoptosis induced by ER stress. ${ }^{11,46}$ Thus, Bax is crucial in ER stress-induced apoptosis. Several pathways of ER stress-induced apoptosis have been reported, in addition to the CHOP pathway. ${ }^{11}$ Therefore, these results do not mean that $\mathrm{CHOP}$-induced apoptosis is mediated solely by Bax. However, our results do show that CHOP expression is able to induce Bax translocation and apoptosis. We also showed that Bax knock down at least partially prevents $\mathrm{CHOP}$-induced apoptosis. The precise mechanism of $\mathrm{CHOP}$-induced Bax translocation remains to be clarified. Recently, Scorrano et al. ${ }^{47}$ reported that Bax and Bak operate at ER as well as mitochondria to maintain homeostasis of $\mathrm{ER} \mathrm{Ca}^{2+}$. We reported that excess $\mathrm{NO}$ increases $\mathrm{Ca}^{2+}$ in cytosol, presumably due to the release from ER. ${ }^{5}$ Therefore, it also remains to be clarified whether there is any interaction between Bax and NO at ER.

\section{hsp70/DnaJ chaperone pair prevents CHOP-induced apoptosis through the inhibition of Bax translocation}

Stress proteins or hsps are a set of conserved proteins the expression of which is induced by various stresses. They have cytoprotective effects and behave as molecular chaperones for cellular proteins. ${ }^{21,22,48,49}$ Under normal conditions, hsp70 family members function as ATP-dependent molecular chaperones by assisting in folding and assembly of newly synthesized polypeptides and their transport to various organelles. Under stress conditions, hsp70 (inducible form) is induced and protects cells from apoptosis. Although the antiapoptotic effects of hsp70 have been noted in several systems, molecular mechanisms are unclear. In heat-induced cell death, hsp70 was reported to inhibit the activation of the stress-activated protein kinase SAPK/JNK (c-Jun N-terminal kinase), the release of cytochrome $c$ and the processing of caspase 3. ${ }^{50,51}$ Gabai et al. ${ }^{52}$ reported that hsp70 specifically interferes with the Bid-dependent apoptotic pathway via inhibition of JNK in tumor necrosis factor- $\alpha$ (TNF $\alpha$ )-induced apoptosis. On the other hand, the site of hsp70 action was suggested to be downstream of caspase 3 in TNF $\alpha$-induced apoptosis. ${ }^{53}$ In addition, the overexpression of hsp70 prevented heat-induced apoptosis, but not Fas-mediated apoptosis in a Jurkat T cell line..$^{54}$ Using in vitro systems, hsp70 was found to prevent apoptosome formation ${ }^{55}$ and caspase 3 activation. ${ }^{56}$ In these studies, however, participation of a DnaJ family member(s) was not given attention. Using in vitro systems, King et al. ${ }^{57}$ showed that the hsc70/dj1 chaperone pair bind to p53 and may regulate the stabilization and localization of p53. We previously found that hsp70-dj1 or dj2 pairs prevent NO-mediated apoptosis upstream of cytochrome $c$ release from the mitochondria in RAW 264.7 cells. ${ }^{29}$ In the present study, we found that hsp70/DnaJ chaperone pairs prevent LPS/IFN- $\gamma$-induced apoptosis downstream of $\mathrm{CHOP}$ induction and upstream of Bax translocation from the cytosol to the mitochondria. We also found that Bax interacts with both hsp70 and dj2. These results suggest that hsp70/ DnaJ chaperone pairs protect cells from apoptosis by binding to Bax and prevent its translocation. As already mentioned, Bax undergoes conformation change before being inserted into mitochondrial outer membrane..$^{36,40,41}$ hsp70/DnaJ pair may prevent Bax from changing into the proapoptotic conformation.

The ATPase domain and C-terminal EEVD motif of hsp70 are essential for chaperone activity. ${ }^{32}$ We report here that the ATPase domain and C-terminal EEVD motif of hsp70 are crucial for antiapoptotic activity in CHOP-induced apoptosis. Similar results were noted in case of TNF $\alpha$-induced apoptosis, ${ }^{52}$ and in heat-shock-induced apoptosis. ${ }^{51}$ These results suggest that the chaperone activity of hsp70 is indispensable in its antiapoptotic activity. We also found that unfarnesylated dj2 mutant decreases its antiapoptotic activity. The role of farnesylation for dj2 chaperone activity remains unknown.

\section{Materials and Methods}

\section{Plasmids}

pcDNA3.1-hsp70, a mammalian expression plasmid for human hsp70, was constructed by inserting the full-length human hsp70 cDNA (GenBank accession number NM_005346) into the EcoRI site of a mammalian expression plasmid pcDNA3.1 $(+)$ (Invitrogen, Carlsbad, CA, USA) that harbors the G418 resistant gene after linker attachment. The mammalian expression plasmids for mutant hsp70 were constructed by inserting the mutated hsp70 cDNA into the EcoRl site of a mammalian expression plasmid pcDNA3.1 $(+)$ after linker attachment. pcDNA3.1-hsp70 $\triangle A T$ Pase express mutant human hsp70 that defect the N-terminal ATPase domain (amino acids 1-380). pcDNA3.1-hsp70 $\triangle$ EEVD express mutant human hsp70 that defect the C-terminal EEVD sequence. The mammalian expression plasmids for human dj1 and dj2 were constructed by inserting the full-length human dj1 or dj2 cDNA into the EcoRI site of a mammalian expression plasmid pcDNA3.1 $(+) /$ Hyg (Invitrogen) that harbors the hygromycin-resistant gene after linker attachment, yielding pcDNA3.1/ Hyg-dj1 and pcDNA3.1/Hyg-dj2. The mammalian expression plasmids for C394S mutant of human dj2 has been described elsewhere. ${ }^{34}$ pcDNA3.1mCHOP, a mammalian expression plasmid for mouse $\mathrm{CHOP}$, was also described previously. ${ }^{7}$ The LacSwitch-inducible mammalian expression system (Stratagene, La Jolla, CA, USA) was used for conditional expression of CHOP. pOPRSVI-CHOP, an IPTG-inducible CHOP expression plasmid, was described. ${ }^{18}$ pUSEamp-Bcl-2 and pUSEamp$\mathrm{Bax}$, the mammalian expression plasmids for mouse Bcl-2 and Bax, respectively, were obtained from Upstate Biotechnology (Lake Placid, NY, USA). pEGFP-C1 and pDsRed-N1, a mammalian expression plasmids for enhanced GFP and DsRed, respectively, were obtained from Clontech Laboratories, Inc. (Palo Alto, CA, USA). The expression plasmid for DsRed with the mitochondria import signal (pDsRed-Mit) was constructed by replacing the EYFP gene of pEYFP-Mito (Clontech Laboratories, Inc.) with DsRed gene. The mammalian expression plasmid for the human active form ATF6 (p50ATF6) was as described. ${ }^{31}$ The mammalian expression plasmids for EGFP-Bcl-2 or EGFP-Bax fusion proteins were constructed by inserting mouse Bcl-2 or Bax full-length cDNA just downstream of the EGFP gene of the plasmid pEGFP-C1 after linker attachment. 


\section{Materials}

Monoclonal antibodies against human/mouse hsc70 and Bax were obtained from Santa Cruz Biotechnology, Inc. (Santa Cruz, CA, USA). Monoclonal antibodies against human hsp70 and human hsp60 were obtained from StressGen Biotechnologies Corp. (Victoria, Canada). Monoclonal antibody against human dj2 was obtained from NeoMarkers (Union City, CA, USA). Polyclonal anti-human dj1 and dj2 antibodies were those described elsewhere. ${ }^{28}$ Monoclonal antibody against mouse iNOS was obtained from Transduction Laboratories (Lexington, KY, USA). A polyclonal antibody against mouse $\mathrm{CHOP}$ and polyclonal and monoclonal antibodies against human Bax were obtained from Santa Cruz Biotechnology Inc. Polyclonal antibody against GFP was as described elsewhere. ${ }^{58}$ Monoclonal antibodies against human/mouse cytochrome $c$ and rabbit GAPDH were obtained from R \& D Systems Inc. (Minneapolis, MN, USA) and CHEMICON International Inc. (Temecula, CA, USA), respectively.

\section{Cell culture and transfection}

Mouse macrophage-like RAW 264.7 cells were grown in Eagle's minimal essential medium supplemented with $10 \%$ fetal calf serum. COS-7 cells and human cervical cancer Hela cells were grown in Dulbecco's modified Eagle's medium supplemented with $10 \%$ fetal calf serum. Mouse peritoneal macrophages were prepared and grown in RPMI 1640 medium supplemented with $10 \%$ fetal calf serum as described. ${ }^{59} \mathrm{CHOP}$ knockout mice were described. ${ }^{5}$ Transfection of cells with siRNA and/or plasmids was carried out using Lipofectamine 2000 (Invitrogen, Carlsbad, CA, USA) according to the protocol provided by the manufacturer. In each experiment, the same total amounts of plasmids were transfected by adding insert-less expression plasmids. To establish stably transformed RAW 264.7 cell line, RAW 264.7 cells were screened with hygromycin $(250 \mu \mathrm{g} / \mathrm{ml})$ and $/$ or $\mathrm{G} 418(500 \mu \mathrm{g} / \mathrm{ml})$ after transfection of plasmids harboring hygromycin or the G418-resistant gene. The sequence of siRNA for human Bax knock down are:

\section{$5^{\prime}-\quad$ GGUGCCGGAACUGAUCAGAdTdT $-3^{\prime}$ \\ $3^{\prime}$-dTdTCCACGGCCUUGACUAGUCU $\quad-5^{\prime}$}

The sequence of siRNA for negative control (mouse Bax sequence) are:

$\begin{array}{ll}5^{\prime}-\text { GGCCUCCUCUCCUACUUCGdTdT } & -3^{\prime} \\ 3^{\prime}-\text { dTdTCCGGAGGAGAGGAUGAAGC } & -5^{\prime}\end{array}$

\section{Treatment of RAW 264.7 cells and mouse peritoneal macrophages}

RAW 264.7 cells were heated at $42^{\circ} \mathrm{C}$ for $2 \mathrm{~h}$ and allowed to recover at $37^{\circ} \mathrm{C}$ for $6 \mathrm{~h}$ then the cell extracts were used as heat-shock-treated extracts. To induce iNOS and NO-mediated apoptosis in RAW 264.7 cells, cells were treated with E. coli LPS (serotype 0127:B8, Sigma Chem. Co., St. Louis, MO, USA, $150 \mu \mathrm{g} / \mathrm{ml})$ plus mouse IFN $\gamma(100 \mathrm{U} / \mathrm{ml})$ for the indicated periods. To induce NO-mediated apoptosis in mouse peritoneal macrophages, cells were treated with a NO donor $S$-nitroso- $N$-acetyl-DLpenicillamine (SNAP, $1.5 \mathrm{mM}$ ) for the indicated periods.

\section{Immunoblot analysis}

RAW 264.7 cells, COS-7 cells or Hela cells were homogenized in $20 \mathrm{mM}$ HEPES-KOH (pH 7.5) containing 1\% Triton X-100, 20\% glycerol and $1 \mathrm{mM}$ dithiothreitol. After centrifugation, the supernatants were used as whole cell extracts for immunoblot analysis. Nuclear extracts from RAW 264.7 cells were prepared, as described, ${ }^{7}$ and used for immunoblot analysis. The cell extracts were then subjected to SDS-polyacrylamide gel electrophoresis, and proteins were electrotransferred to nitrocellulose membranes. Immunodetection was performed using the ECL kit (Amersham, Buckinghamshire, UK) according to the protocol provided by the manufacturer.

\section{Measurement of NO production}

Concentration of $\mathrm{NO}_{2}^{-}$plus $\mathrm{NO}_{3}^{-}$in culture supernatants was measured, as described. ${ }^{29}$

\section{Detection of apoptosis}

RAW 264.7 cells or Hela cells were treated as described above. Detection of DNA ladder formation was done, as described ${ }^{29}$ Caspase 3 activity was measured, as described. ${ }^{29}$ To detect mitochondrial membrane potential disruption, cells were stained with a membrane potential-dependent dye DePsipher (Trevigen Inc., Gaithersburg, MD, USA), as described. ${ }^{5}$ To analyze morphological changes in nuclei, the cells were fixed, stained with Hoechst dye $33258(8 \mu \mathrm{g} / \mathrm{ml})$ for $5 \mathrm{~min}$, and washed with phosphatebuffered saline. The stained cells were then observed under a fluorescence microscope.

\section{Subcellular fractionation}

Cell fractionation was done, as described. ${ }^{29}$ Briefly, the cell suspension (about $5 \times 10^{7}$ cells $/ \mathrm{ml}$ ) was mixed with an equal volume of digitonin $\left(1 \mathrm{mg} / \mathrm{ml}\right.$ ) in phosphate-buffered saline (PBS), incubated at $25^{\circ} \mathrm{C}$ for $5 \mathrm{~min}$, then kept on ice for $5 \mathrm{~min}$ then centrifuged at $15000 \times g$ for $2 \mathrm{~min}$. The supernatant served as the soluble fraction. The pellet containing mitochondria was dissolved in $0.5 \%$ Triton X-100 in PBS, insoluble material was removed by centrifugation, and the supernatant served as the particulate fraction.

\section{Immunocytochemical staining}

RAW 264.7 cells and mouse peritoneal macrophages were cultured on coverslips and treated as indicated. The cells were fixed with $4 \%$ paraformaldehyde for $40 \mathrm{~min}$ at room temperature and treated with phosphate-buffered saline containing $1 \%$ Triton X-100. The cells were incubated with first antibodies, and then with second antibodies conjugated with Alexa Fluor (Molecular Probes, Eugene, OR, USA). The stained cells were observed using a fluorescence microscope.

\section{Co-immunoprecipitation of Bax and hsp70-dj2}

Raw 264.7 cells or COS-7 cells were lysed in CelLytic MT Mammalian Tissue Lysis/extraction Reagent (Amersham). The cell lysates were centrifuged at $25000 \times \mathrm{g}$ for $15 \mathrm{~min}$ at $4^{\circ} \mathrm{C}$. The supernatant fractions $(1 \mathrm{ml}, 300 \mu \mathrm{g}$ of protein) were incubated with an anti-Bax polyclonal antibody or control $\operatorname{lgG}$ (nonimmune rabbit $\operatorname{lgG}$ ) for $1 \mathrm{~h}$ at $20^{\circ} \mathrm{C}$ then $100 \mu \mathrm{l}$ of a $12 \%$ suspension of protein A-Sepharose (Amersham) was added. After mixing for $1 \mathrm{~h}$ at $20^{\circ} \mathrm{C}$, the resin was collected by centrifugation and washed three times with wash buffer $(50 \mathrm{mM}$ Tris- $\mathrm{HCl}(\mathrm{pH} 7.5)$ containing $150 \mathrm{mM} \mathrm{NaCl}, 5 \mathrm{mM}$ EDTA, 0.1\% Triton X-100). Proteins were extracted and subjected to immunoblot analysis, using monoclonal antibodies against Bax, hsp70, hsc70, dj1, or dj2. 


\section{Acknowledgements}

We thank Kazutoshi Mori (Kyoto University, Japan) for providing an expression plasmid for p50ATF6, Shizuo Akira (Osaka University, Japan) for CHOP knockout mice and pOPRSVI-CHOP, an inducible expression plasmid for $\mathrm{CHOP}$, our colleagues for suggestions and discussion and $\mathrm{M}$ Ohara for comments on the manuscript. This work was supported in part by Grants-in-Aid (14370047 to M Mori and 13670124 to T Gotoh) from the Ministry of Education, Science, Technology, Sports, and Culture of Japan, and a grant (to T Gotoh) from TAKEDA SCIENCE FOUNDATION.

\section{References}

1. Ignarro LJ (2000) Nitric Oxide; Biology and Pathology. (London: Academic Press)

2. Dimmeler S and Zeiher AM (1997) Nitric oxide and apoptosis: another paradigm for the double-edged role of nitric oxide. Nitric Oxide 1: 275-281

3. Kröncke KD, Fehsel K and Kolb-Bachofen V (1997) Nitric oxide: cytotoxicity versus cytoprotection - how, why, when, and where? Nitric Oxide 1: 107-120

4. Boyd CS and Cadenas E (2002) Nitric oxide and cell signaling pathways in mitochondrial-dependent apoptosis. Biol. Chem. 383: 411-423

5. Oyadomari S, Takeda K, Takiguchi M, Gotoh T, Matsumoto M, Wada I, Akira S, Araki $\mathrm{E}$ and Mori $\mathrm{M}$ (2001) Nitric oxide-induced apoptosis in pancreatic $\beta$ cells is mediated by the endoplasmic reticulum stress pathway. Proc. Natl. Acad. Sci. USA 98: 10845-10850

6. Kawahara K, Oyadomari S, Gotoh T, Kohsaka S, Nakayama H and Mori M (2001) Induction of CHOP and apoptosis by nitric oxide in p53-deficient microglial cells. FEBS Lett. 506: 135-139

7. Gotoh T, Oyadomari S, Mori K and Mori M (2002) Nitric oxide-induced apoptosis in RAW 264.7 macrophages is mediated by endoplasmic reticulum stress pathway involving ATF6 and CHOP. J. Biol. Chem. 277: 12343-12350

8. Sidrauski C, Chapman R and Walter P (1998) The unfolded protein response: an intracellular signalling pathway with many surprising features. Trends Cell Biol. 8: 245-249

9. Zinszner $H$, Kuroda M, Wang X, Batchvarova N, Lightfoot RT, Remotti $H$, Stevens JL and Ron D (1998) CHOP is implicated in programmed cell death in response to impaired function of the endoplasmic reticulum. Genes Dev. 12: 982-995

10. Kaufman RJ (1999) Stress signaling from the lumen of the endoplasmic reticulum: coordination of gene transcriptional and translational controls. Genes Dev. 13: 1211-1233

11. Ferri KF and Kroemer G (2001) Organelle-specific initiation of cell death pathways. Nat. Cell Biol. 3: E255-E263

12. Ma $Y$ and Hendershot LM (2001) The unfolding tale of the unfolded protein response. Cell 107: 827-830

13. Yoshida H, Matsui T, Yamamoto A, Okada T and Mori K (2001) XBP1 mRNA is induced by ATF6 and spliced by IRE 1 in response to ER stress to produce a highly active transcription factor. Cell 107: 881-891

14. Calfon M, Zeng H, Urano F, Till JH, Hubbard SR, Harding HP, Clark SG and Ron D (2002) IRE1 couples endoplasmic reticulum load to secretory capacity by processing the XBP-1 mRNA. Nature 415: 92-96

15. Lee K, Tirasophon W, Shen X, Michalak M, Prywes R, Okada T, Yoshida H, Mori $K$ and Kaufman RJ (2002) IRE1-mediated unconventional mRNA splicing and S2P-mediated ATF6 cleavage merge to regulate XBP1 in signaling the unfolded protein response. Genes Dev. 16: 452-466

16. Fawcett TW, Martindale JL, Guyton KZ, Hai T and Holbrook NJ (1999) Complexes containing activating transcription factor (ATF)/cAMP-responsiveelement-binding protein (CREB) interact with the CCAAT/enhancer-binding protein (C/EBP)-ATF composite site to regulate Gadd153 expression during the stress response. Biochem. J. 339: 135-141

17. Harding HP, Novoa I, Zhang Y, Zeng H, Wek R, Schapira M and Ron D (2000) Regulated translation initiation controls stress-induced gene expression in mammalian cells. Mol. Cell 6: 1099-1108

18. Matsumoto M, Minami M, Takeda K, Sakao Y and Akira S (1996) Ectopic expression of CHOP (GADD153) induces apoptosis in M1 myeloblastic leukemia cells. FEBS Lett. 395: 143-147
19. Wang X Z, Kuroda M, Sok J, Batchvarova N, Kimmel R, Chung P, Zinszner H and Ron D (1998) Identification of novel stress-induced genes downstream of chop. EMBO J. 17: 3619-3630

20. McCullough KD, Martindale JL, Klotz LO, Aw TY and Holbrook NJ (2001) Gadd153 sensitizes cells to endoplasmic reticulum stress by down-regulating Bcl2 and perturbing the cellular redox state. Mol. Cell. Biol. 21: 1249-1259

21. Samali A and Orrenius S (1998) Heat shock proteins: regulators of stress response and apoptosis. Cell Stress Chaperones 3: 228-236

22. Smith DF, Whitesell $L$ and Katsanis E (1998) Molecular chaperones: biology and prospects for pharmacological intervention. Pharmacol. Rev. 50: 493-514

23. Bukau B and Horwich AL (1998) The Hsp70 and Hsp60 chaperone machines. Cell 92: 351-366

24. Johnson JL and Craig EA (1997) Protein folding in vivo: unraveling complex pathways. Cell 90: 201-204

25. Netzer WJ and Hartl FU (1998) Protein folding in the cytosol: chaperonindependent and -independent mechanisms. Trends Biochem. Sci. 23: 68-73

26. Laufen T, Mayer MP, Beisel C, Klostermeier D, Mogk A, Reinstein J and Bukau B (1999) Mechanism of regulation of hsp70 chaperones by DnaJ cochaperones. Proc. Natl. Acad. Sci. USA 96: 5452-5457

27. Kelley WL (1998) The J-domain family and the recruitment of chaperone power. Trends Biochem Sci. 23: 222-227

28. Terada K, Kanazawa M, Bukau B and Mori M (1997) The human DnaJ homologue dj2 facilitates mitochondrial protein import and luciferase refolding. J. Cell Biol. 139: 1089-1095

29. Gotoh T, Terada K and Mori M (2001) hsp70-DnaJ chaperone pairs prevent nitric oxide-mediated apoptosis in RAW 264.7 macrophages. Cell Death Differ. 8: 357-366

30. Gotoh T and Mori M (1999) Arginase II downregulates nitric oxide (NO) production and prevents NO- mediated apoptosis in murine macrophagederived RAW 264.7 cells. J. Cell Biol. 144: 427-434

31. Yoshida H, Okada T, Haze K, Yanagi H, Yura T, Negishi M and Mori K (2000) ATF6 activated by proteolysis binds in the presence of NF-Y (CBF) directly to the cis-acting element responsible for the mammalian unfolded protein response. Mol. Cell. Biol. 20: 6755-6767

32. Demand J, Luders J and Hohfeld J (1998) The carboxy-terminal domain of Hsc70 provides binding sites for a distinct set of chaperone cofactors. Mol. Cell. Biol. 18: 2023-2028

33. Ballinger CA, Connell P, Wu Y, Hu Z, Thompson LJ, Yin LY and Patterson C (1999) Identification of CHIP, a novel tetratricopeptide repeat-containing protein that interacts with heat shock proteins and negatively regulates chaperone functions. Mol. Cell. Biol. 19: 4535-4545

34. Kanazawa M, Terada K, Kato S and Mori M (1997) HSDJ, a human homolog of DnaJ, is farnesylated and is involved in protein import into mitochondria. J. Biochem. (Tokyo) 121: 890-895

35. Wang X (2001) The expanding role of mitochondria in apoptosis. Genes Dev. 15: 2922-2933

36. Makin GW, Corfe BM, Griffiths GJ, Thistlethwaite A, Hickman JA and Dive C (2001) Damage-induced Bax N-terminal change, translocation to mitochondria and formation of Bax dimers/complexes occur regardless of cell fate. EMBO J. 20: $6306-6315$

37. Green DR and Reed JC (1998) Mitochondria and apoptosis. Science 281: 1309-1312

38. Kaufmann SH and Hengartner MO (2001) Programmed cell death: alive and well in the new millennium. Trends Cell Biol. 11: 526-534

39. Wei MC, Zong WX, Cheng, EH, Lindsten T, Panoutsakopoulou V, Ross AJ, Roth KA, MacGregor GR, Thompson CB and Korsmeyer SJ (2001) Proapoptotic BAX and BAK: a requisite gateway to mitochondrial dysfunction and death. Science 292: 727-730

40. Suzuki M, Youle RJ and Tjandra N (2000) Structure of Bax: coregulation of dimer formation and intracellular localization. Cell 103: 645-654

41. Degterev A, Boyce M and Yuan J (2001) The channel of death. J. Cell Biol. 155: 695-698

42. Gross A, Jockel J, Wei MC and Korsmeyer SJ (1998) Enforced dimerization of $\mathrm{BAX}$ results in its translocation, mitochondrial dysfunction and apoptosis. EMBO J. 17: 3878-3885

43. Shimizu S, Matsuoka Y, Shinohara Y, Yoneda Y and Tsujimoto Y (2001) Essential role of voltage-dependent anion channel in various forms of apoptosis in mammalian cells. J. Cell Biol. 152: 237-250 
44. Callsen D and Brüne B (1999) Role of mitogen-activated protein kinases in $S$-nitrosoglutathione-induced macrophage apoptosis. Biochemistry 38 : 2279-2286

45. Jun CD, Oh CD, Kwak HJ, Pae HO, Yoo JC, Choi BM, Chun JS, Park RK and Chung HT (1999) Overexpression of protein kinase C isoforms protects RAW 264.7 macrophages from nitric oxide-induced apoptosis: involvement of c-Jun $\mathrm{N}$-terminal kinase/stress-activated protein kinase, p38 kinase, and CPP-32 protease pathways. J. Immunol. 162: 3395-3401

46. Zong WX, Lindsten T, Ross AJ, MacGregor GR and Thompson CB (2001) $\mathrm{BH} 3-$ only proteins that bind pro-survival $\mathrm{Bcl}-2$ family members fail to induce apoptosis in the absence of Bax and Bak. Genes Dev. 15: 1481-1486

47. Scorrano L, Oakes SA, Opferman JT, Cheng EH, Sorcinelli MD, Pozzan T and Korsmeyer SJ (2003) BAX and BAK regulation of endoplasmic reticulum $\mathrm{Ca}^{2+}$ : a control point for apoptosis. Science 300: 135-139

48. Beere HM and Green R (2001) Stress management-heat shock protein-70 and the regulation of apoptosis. Trends Cell Biol. 11: 6-10

49. Garrido C, Gurbuxani S, Ravagnan L and Kroemer G (2001) Heat shock proteins: endogenous modulators of apoptotic cell death. Biochem. Biophys. Res. Commun. 286: 433-442

50. Mosser DD, Caron AW, Bourget L, Denis-Larose C and Massie B (1997) Role of the human heat shock protein hsp70 in protection against stress-induced apoptosis. Mol. Cell. Biol. 17: 5317-5327

51. Mosser DD, Caron AW, Bourget L, Meriin AB, Sherman MY, Morimoto RI and Massie B (2000) The chaperone function of hsp70 is required for protection against stress-induced apoptosis. Mol. Cell. Biol. 20: 7146-7159
52. Gabai VL, Mabuchi K, Mosser DD and Sherman MY (2002) Hsp72 and stress kinase c-jun N-terminal kinase regulate the bid-dependent pathway in tumor necrosis factor-induced apoptosis. Mol. Cell. Biol. 22: 3415-3424

53. Jäättelä M, Wissing D, Kokhol K, Kallunki T and Egeblad M (1998) Hsp70 exerts its anti-apoptotic function downstream of caspase-3-like proteases. EMBO J. 17: 6124-6134

54. Liossis S-NC, Ding XZ, Kiang JG and Tsokos GC (1997) Overexpression of the heat shock protein 70 enhances the TCR/CD3- and Fas/Apo-1/CD95-mediated apoptotic cell death in Jurkat T cells. J. Immunol. 158: 5668-5675

55. Beere HM, Wolf BB, Cain K, Mosser DD, Mahboubi A, Kuwana T, Tailor P, Morimoto RI, Cohen GM and Green DR (2000) Heat-shock protein 70 inhibits apoptosis by preventing recruitment of procaspase- 9 to the Apaf-1 apoptosome. Nat. Cell Biol. 2: 469-475

56. Li CY, Lee JS, Ko YG, Kim Jl and Seo JS (2000) Heat shock protein 70 inhibits apoptosis downstream of cytochrome $c$ release and upstream of caspase-3 activation. J. Biol. Chem. 275: 25665-25671

57. King FW, Wawrzynow A, Hohfeld J and Zylicz M (2001) Co-chaperones Bag-1, $\mathrm{Hop}$ and $\mathrm{Hsp} 40$ regulate $\mathrm{Hsc70}$ and $\mathrm{Hsp} 90$ interactions with wild-type or mutant p53. EMBO J. 20: 6297-6305

58. Yano M, Kanazawa M, Terada K, Takeya M, Hoogenraad N and Mori M (1998) Functional analysis of human mitochondrial receptor Tom20 for protein import into mitochondria. J. Biol. Chem. 273: 26844-26851

59. Salimuddin, Nagasaki A, Gotoh T, Isobe H and Mori M (1999) Regulation of the genes for arginase isoforms and related enzymes in mouse macrophages by lipopolysaccharide. Am. J. Physiol. 277: E110-E117 